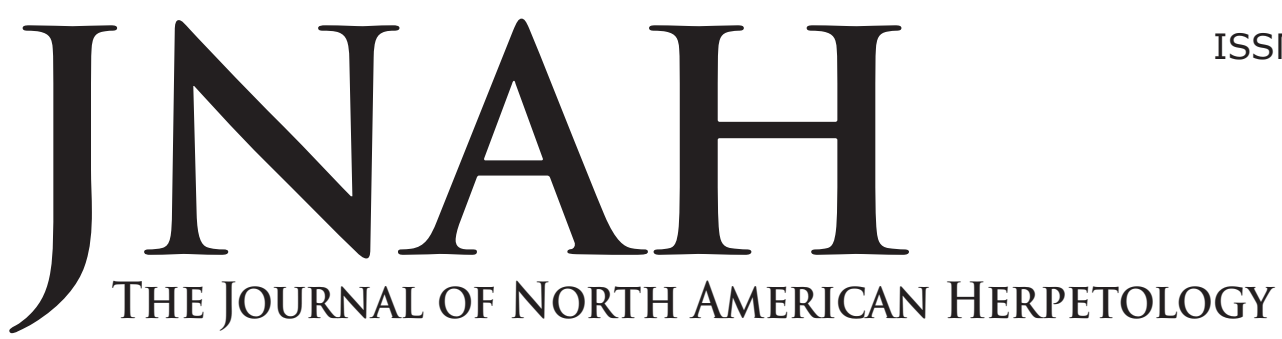

ISSN 2333-0694

Volume 2020, Number 1

2 July 2020

journals.ku.edu/jnah

\title{
DO LATITUDE, ELEVATION, TEMPERATURE, AND PRECIPITATION INFLUENCE BODY AND CLUTCH SIZES OF FEMALE COMMON FIVE-LINED SKINKS, PLESTIODON FASCIATUS (LINNAEUS, 1758)?
}

\author{
JAKE S. MORRISSEY ${ }^{1}$, BRANDON BARR ${ }^{1}$, ANDREW E. AUSTIN $^{1}$, \\ LAUREN R. BABCOCK ${ }^{1}$, AND ROBERT POWELL ${ }^{1,2}$
}

${ }^{1}$ Department of Biology, Avila University, Kansas City, Missouri 64145, USA

${ }^{2}$ Corresponding author. E-mail: robert.powell@avila.edu

\begin{abstract}
Common Five-lined Skinks (Plestiodon fasciatus) have an extensive distribution that includes much of eastern North America. We examined 490 female specimens (274 with putative clutch sizes) from throughout the range to see if latitude, elevation, mean annual temperature, and/or mean annual precipitation affected body or clutch sizes. We predicted that larger females would produce larger clutches, latitude and elevation would negatively affect both body and clutch sizes, and that temperature and precipitation would exert a positive effect. Our results did not consistently support those predictions. Body size was positively associated with latitude, negatively associated with temperature, and not associated with elevation or precipitation. Clutch size was not related to female body size, but in most instances was positively associated with temperature and precipitation but negatively associated with elevation and latitude. Effectively $K$-selected in the North and $r$-selected in the South, body and clutch sizes in this species appear to be responding to different selective pressures. We evaluated probable causes for the opposite trends in these two life-history traits.
\end{abstract}

Key Words: Bergmann's rule; r- and K-selection; Resource rule; Temperature-size rule.

\section{INTRODUCTION}

Data regarding the effects of latitude, elevation, temperature, or precipitation on body size and reproductive output of squamate reptiles (lizards and snakes) are equivocal. Bergmann's rule (Bergmann, 1847) states that homeotherms are larger in colder climates. Cooler conditions often reflect increasing latitude or elevation, implying that homeotherms at higher latitudes or elevations are larger. However, responses of ectotherms to these environmental variables vary. For example, Ashton and Feldman (2003) indicated that turtles appear to follow Bergmann's rule, whereas squamates show an opposite trend (but see the discussions in Angilletta et al., 2004 and Pincheira-Donoso and Meiri, 2013). Contradicting Ashton and Feldman's (2003) conclusions, Howes and Lougheed (2007) found that male body size in Common Five-lined Skinks (Plestiodon fasciatus) increased significantly with increasing latitude, and Aragón and Fitze (2014), in a study of Spanish snakes (Psammodromus spp.), found a significant negative association between temperature and snout-vent length (SVL) and a signif- icant positive relationship between elevation and SVL. Further complicating matters is the temperature-size rule (e.g., Angilletta and Dunham, 2003; Stillwell, 2010), which states that cooler conditions can retard growth and delay maturation. Like Bergmann's rule, it would predict a negative association between temperature and adult size.

An alternative explanation, the resource rule (McNab, 2010), suggests that primary productivity and precipitation and resultant greater resource availability are the primary determinants of animal body sizes. Again, data for ectotherms are equivocal. For example, Pincheira-Donoso and Meiri (2013) indicated that various studies collectively revealed "no support for patterns" and "no signals of processes." However, Amarello et al. (2010) indicated that body sizes in Western Diamond-backed Rattlesnakes (Crotalus atrox) increased in colder and wetter (i.e., more productive) areas, whereas Oufiero et al. (2011) and Volynchik (2012) showed that the size of lizards in the genus Sceloporus and that of the Palestine Viper (Vipera palaestinae), respectively, increased in 
arid areas. Tracy (1999) found no association between body size and food abundance in Common Chuckwallas (Sauromalus ater), and Aragón and Fitze (2014) found a relationship between body size and primary productivity in Spanish Sand Racers (Psammodromus spp.) only after correcting for phylogenetic inertia and short-term seasonal variation. Mesquita et al. (2016) examined 674 lizard populations, representing 297 species from 263 sites from throughout the world, and concluded that climatic factors exerted a significant influence on adult female mass, adult female SVL, female SVL at maturity, clutch size, offspring SVL, and relative clutch mass (RCM). However, all regressions showed very low effect sizes, indicative of extensive unexplained variation in the data, some of which was attributed to sampling error common to ecological studies with large data sets.

Climatic factors and/or resource abundance might not fully explain variations in animal body size, but also could interact with biotic factors, such as competition or predation. For example, in a study of the herpetofauna of southern Florida, Meshaka and Layne (2015) noted that geographic variation in body size in several species was associated with the presence or absence of presumably competing congeners.

Olalla-Tárraga et al. (2006) concluded that "although body size influences the energy balance of thermoregulating ectotherms, inconsistent biogeographical patterns and contrasting associations with energy in lizards and snakes suggest that no single mechanism can explain variation of reptile body size in the northern temperate zone." Regardless, if environmental factors like latitude, elevation, temperature, or precipitation directly or indirectly affect female body size, we should see a comparable association with clutch size, since larger females produce larger clutches in many reptiles (e.g., Shine, 1988 and references therein). For example, Abell (1999) demonstrated that the Striped Plateau Lizard (Sceloporus virgatus) showed positive associations between body size, clutch size, and precipitation.

We examined 490 female Common Five-lined Skinks, Plestiodon fasciatus (Linnaeus, 1758) from throughout the species' range to see if latitude, elevation, temperature, or precipitation affected body and/or clutch sizes. Common Five-lined Skinks are widely distributed throughout eastern North America (Fig. 1), ranging from eastern Texas and Kansas to the East Coast and from northern Florida and the Gulf Coast to southern Canada (Powell et al., 2016). Howes et al. (2006) identified seven mitochondrial lineages in the species, but Howes and Lougheed (2007) found no significant differences in body size among lineages.

These lizards are closely associated with moist wooded areas (Smith, 1946; Hecnar, 1994; Hecnar and M'Closkey, 1998), where they prey on insects and other small invertebrates (e.g., Fitch, 1954; Harding, 1997; Brazeau et al., 2015). Activity varies across the species' range. In Canadian populations, hibernation may begin as early as late August and extend through late September, with emergence in mid-April to early May (Seburn, 1990; Seburn and Seburn, 1998; Wick, 2004). In Kansas, hibernation typically extends from late September through mid-October to mid- to late-March and early April (Fitch, 1954). Skinks in Georgia generally emerge from hibernation by April (Vitt and Cooper, 1986).

Smith (1946) and Vitt and Cooper (1986) indicated that females reach sexual maturity at two years of age and SVL of $52 \mathrm{~mm}$. Fitch (1954) noted that Kansas fe- males reached maturity at $60 \mathrm{~mm}$ SVL, but suggested that sexual maturity varies across the species' range, with some individuals in southern populations reaching breeding size during their first summer, whereas many lizards in northern regions may not reach that size until their third summer. However, Seburn and Seburn (1998) noted that some individuals in a Canadian population achieved minimum breeding size during their first summer, although those skinks likely did not reproduce until their second summer.

Clutch sizes range from one to 19 eggs (Hecnar and Hecnar, 2019), with numbers reflecting the size, age, and condition of the female (Fitch, 1954; Hecnar and Hecnar, 2005). Smith (1946) and Vitt and Cooper (1986) stated that females have an average gestation period of six to seven weeks. However, Seburn and Seburn (1998) noted that gravid females in a Canadian population retained eggs for 52 days and brooded them for 13 days, whereas Fitch (1954) recorded egg retention of 30-44 days and brooding of 11-32 days in Kansas. Seburn and Seburn (1998) suggested that the differences most likely reflected compensation for a shorter active season in the northern population. Initiation and duration of incubation vary across the species' range and within populations (Noble and Mason, 1933; Fitch, 1954). Hatching generally occurs by mid-July in Kansas (Fitch, 1954), whereas in Canadian populations, hatching ranges from late July to early August (Seburn and Seburn, 1989; Seburn, 1990). However, Vitt and Cooper (1986) indicated that hatching in Georgia occurs from mid-July through mid-August and Palmer and Braswell (1995) listed hatching dates ranging from early July to early September. Surprisingly, these southeastern records are more similar to that of northern populations than those in Kansas.

Fitch (1954) recorded hatchling SVL of 23-27 mm, with rapid growth to $\sim 50 \mathrm{~mm}$ SVL prior to hibernation in Kansas. Canadian hatchlings grew less rapidly $(0.18-0.26$ $\mathrm{mm} /$ day vs. $\sim 0.5 \mathrm{~mm}$ /day in Kansas), but maximum SVL entering hibernation was $48 \mathrm{~mm}$ (Seburn, 1990). Adult growth rates in Canada were $0.02 \mathrm{~mm} /$ day in males and $0.08 \mathrm{~mm} /$ day in females. Howes and Lougheed (2007) found a significant sex-specific latitudinal cline in sexual size dimorphism (SSD), with male body size increasing at higher latitudes while female body size remained relatively constant.

Based on data presented by Fitch (1954) and Hecnar and Hecnar $(2005,2019)$, we predicted that larger females would bear larger clutches. Based on the inverse of Bergmann's rule (e.g., Ashton and Feldman, 2003 but see Howes and Lougheed, 2007) and the resource rule (but see discussions in Pincheira-Donoso and Meiri, 2013 and Mesquita et al., 2016), we predicted that latitude and elevation would negatively affect both body and clutch sizes and that temperature and precipitation would exert a positive effect.

\section{MATERIALS AND METHODS}

We examined preserved museum specimens (Appendix 1) from Alabama, Arkansas, Delaware, Georgia, Illinois, Florida, Kansas, Kentucky, Louisiana, Massachusetts, Michigan, Minnesota, Mississippi, Missouri, North Carolina, Ohio, Oklahoma, Ontario (Canada), South Carolina, Ohio, Tennessee, Texas, Wisconsin, and Virginia (Fig. 1). We made incisions through the abdominal wall from the xiphoid process to the pelvic girdle. After determining the sex of each specimen, we eliminated males and considered only females in subsequent analyses. We 


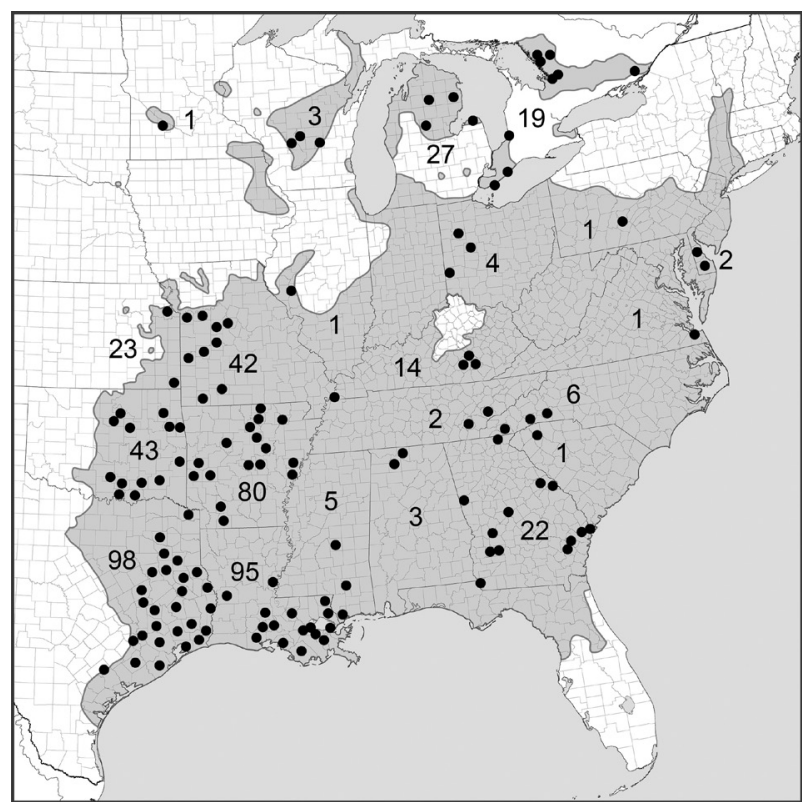

Fig. 1. The range of Common Five-lined Skinks (Plestiodon fasciatus). Dots mark localities where specimens used in this study were collected. Some dots represent multiple sites in close proximity. Numbers indicate sample sizes from states/provinces.

counted yolked ovarian (= vitellogenic) follicles (based on yellowish coloration) and oviductal eggs, and measured snout-vent length (SVL) to the nearest $0.1 \mathrm{~mm}$ using a digital caliper (Mitutoyo Corp., Aurora, IL). We acquired elevation, temperature, and precipitation data from the local weather stations nearest to the sites where specimens had been collected (https://www.idcide.com/ weather/index.htm).

We defined four categories of females for our analyses: Category 1 = all females; Category 2 = all females with SVL $\geq 33.2 \mathrm{~mm}$ (the smallest female in our sample with evidence of vitellogenesis) with either yolked ovarian follicles or oviductal eggs (in effect excluding those individuals for which clutch-size data were unavailable; these presumably were either juveniles that had not yet begun diverting resources from growth to vitellogenesis or adults that had just deposited eggs and had not begun yolking the next clutch); Category $3=$ females with either yolked ovarian follicles or oviductal eggs and SVL > 52 $\mathrm{mm}$, the size at which Vitt and Cooper (1986) indicated female maturity was attained; and Category $4=$ females with SVL > $52 \mathrm{~mm}$ and with clutch sizes determined solely by the presence of oviductal eggs (to eliminate the possibility that not all vitellogenic follicles develop into oviductal eggs; e.g., Ramírez-Pinilla et al., 2014).

We used StatView 5.0 (SAS Institute Inc., Cary, North Carolina) for all statistical tests. Means are reported \pm SE. For all tests, $a=0.05$. To assure normality, we $\log _{10}$-transformed all data. Because environmental variables were not independent and we wanted to assess the relative effects of each factor, we ran simple regression analyses for SVL versus clutch size and for both SVL and clutch size versus latitude $\left({ }^{\circ}\right)$, elevation $(m)$, mean annual temperature $\left({ }^{\circ} \mathrm{C}\right)$, and mean annual precipitation $(\mathrm{cm})$.

\section{RESULTS}

Means and ranges of body sizes for all four categories of specimens and of clutch sizes for categories 2-4 are in Table 1, which also lists means and ranges of environmental variables (latitude, elevation, mean annual temperature, mean annual precipitation) for each category.

All environmental variables were significantly correlated. Mean annual temperature and precipitation were negatively associated with both latitude and elevation, mean annual temperature and precipitation were positively associated, and latitude and elevation also were positively associated (all $P<0.0001$ )

Associations of body size (SVL) with clutch size and of SVL and clutch size with environmental variables (latitude, elevation, mean annual temperature, mean annu-

TABLE 1. Means ( $\pm 1 \mathrm{SE}$ ) and ranges (in parentheses) for SVL $(\mathrm{mm})$ and clutch size in four categories of female Common Five-lined Skinks (Plestiodon fasciatus) and the environmental variables (latitude, elevation, mean annual temperature, mean annual precipitation) applicable to each category. Category $1=$ all females with SVL $\geq 26.8 \mathrm{~mm}$; Category 2 = all females with SVL $\geq 26.8 \mathrm{~mm}$ and with yolked ovarian follicles or oviductal eggs; Category $3=$ females with SVL $>52 \mathrm{~mm}$ and with either yolked ovarian follicles or oviductal eggs; Category 4 = females with SVL $>52 \mathrm{~mm}$ and only oviductal eggs. Clutch-size data were not analyzed and are omitted for Category 1. Clutch sizes based on either yolked ovarian follicles or oviductal eggs are marked with an asterisk (*; see text); those based solely on the presence of oviductal eggs are marked with a double asterisk $(* *)$.

\begin{tabular}{|c|c|c|c|c|}
\hline $\begin{array}{l}\text { Environmental } \\
\text { Variables }\end{array}$ & $\begin{array}{l}\text { Category } 1(n=489) \\
56.9 \pm 0.4(26.8-85.2)\end{array}$ & $\begin{array}{c}\text { Category } 2(n=274) \\
58.9 \pm 0.5(33.2-75.0) \\
12.4 \pm 0.3(5-26)^{*}\end{array}$ & $\begin{array}{c}\text { Category } 3(n=212) \\
62.8 \pm 0.4(52.1-75.0) \\
12.2 \pm 0.3(5-26)^{*}\end{array}$ & $\begin{array}{l}\text { Category } 4(n=156) \\
62.5 \pm 0.4(53.1-75.0) \\
10.0 \pm 0.2(5-15)^{* *}\end{array}$ \\
\hline Latitude $\left({ }^{\circ} \mathrm{N}\right)$ & $\begin{array}{c}34.6 \pm 0.2 \\
(26.7-45.6)\end{array}$ & $\begin{array}{c}33.9 \pm 0.3 \\
(29.0-45.3)\end{array}$ & $\begin{array}{c}34.4 \pm 0.3 \\
(29.6-45.3)\end{array}$ & $\begin{array}{c}35.1 \pm 0.4 \\
(29.8-45.3)\end{array}$ \\
\hline Elevation (m) & $\begin{array}{l}130.0 \pm 5.1 \\
(0.9-715.0)\end{array}$ & $\begin{array}{l}106.5 \pm 6.7 \\
(0.9-684.0)\end{array}$ & $\begin{array}{l}109.2 \pm 7.1 \\
(0.9-591.6)\end{array}$ & $\begin{array}{l}120.7 \pm 8.3 \\
(0.9-591.6)\end{array}$ \\
\hline $\begin{array}{c}\text { Mean Annual } \\
\text { Temperature }\left({ }^{\circ} \mathrm{C}\right)\end{array}$ & $\begin{array}{l}16.1 \pm 0.2 \\
(4.2-24.1)\end{array}$ & $\begin{array}{l}16.7 \pm 0.3 \\
(5.5-21.1)\end{array}$ & $\begin{array}{l}16.2 \pm 0.3 \\
(5.5-21.1)\end{array}$ & $\begin{array}{l}15.5 \pm 0.4 \\
(5.5-21.1)\end{array}$ \\
\hline $\begin{array}{c}\text { Mean Annual } \\
\text { Precipitation }(\mathrm{cm})\end{array}$ & $\begin{array}{c}125.5 \pm 1.1 \\
(70.8-175.1)\end{array}$ & $\begin{array}{c}127.8 \pm 1.6 \\
(74.2-167.6)\end{array}$ & $\begin{array}{c}126.3 \pm 1.8 \\
(74.2-167.6)\end{array}$ & $\begin{array}{l}123.3 \pm 2.0 \\
(74.2-167.6)\end{array}$ \\
\hline
\end{tabular}


al precipitation) are in Table 2. Body and clutch sizes were not significantly related in any category (Fig. 2). Body sizes (Fig. 3) were positively associated with latitude, negatively associated with mean annual temperature, and not significantly associated with elevation in all categories; body sizes were negatively associated with mean annual precipitation only for Category 4, although relationships approached significance for Categories 1 and 3. Clutch sizes (Fig. 4) were negatively associated with latitude and elevation but positively associated with mean annual temperature for Categories 2 and 3 but not 4. The association with mean annual precipitation was significant for Category 2, approached significance for Category 3, but was not significant for Category 4.

\section{DISCUSSION}

Environmental variables.-Relationships between the environmental variables examined in this study were largely as expected. The negative relationship between temperature and both latitude and elevation has been well documented (e.g., Birdsall et al., 2017). Similarly, Zhao and Khalil (1993) demonstrated that precipitation and temperature are frequently and positively associated (although warm summers in temperate zones are typically dryer), and higher latitudes or elevations often are inversely associated with precipitation. The positive relationship between latitude and elevation could merely reflect sampling bias, as the lowest elevations in our sample were largely in the southern Coastal Plain and northern sampling sites were generally far from coastal areas.

TABLE 2. Results of simple regression analyses of $\log _{10}$-transformed SVL $(\mathrm{mm})$ versus clutch size and both SVL (mm) and clutch size versus latitude $\left({ }^{\circ}\right)$, elevation $(\mathrm{m})$, mean annual temperature $\left({ }^{\circ} \mathrm{C}\right)$, and mean annual precipitation ( $\mathrm{cm}$ ) in female Common Five-lined Skinks (Plestiodon fasciatus). Significant relationships are indicated with an asterisk ( $*$ ). Category $1=$ all females with SVL $\geq 26.8$ $\mathrm{mm}$; Category 2 = all females with SVL $\geq 26.8 \mathrm{~mm}$ and with yolked ovarian follicles or oviductal eggs; Category $3=$ females with SVL $>52 \mathrm{~mm}$ and with either yolked ovarian follicles or oviductal eggs; Category $4=$ females with SVL > 52 mm and only oviductal eggs.

\begin{tabular}{|c|c|c|c|c|c|c|}
\hline \multirow[b]{2}{*}{ Variables } & \multicolumn{2}{|c|}{$\begin{array}{c}\text { Categories } 1 \& 2 \\
(n=489, n=274 \\
\text { for clutch size })\end{array}$} & \multicolumn{2}{|c|}{$\begin{array}{l}\text { Category } 3 \\
(n=212)\end{array}$} & \multicolumn{2}{|c|}{$\begin{array}{l}\text { Category } 4 \\
(n=156)\end{array}$} \\
\hline & $\boldsymbol{r}^{2}$ & $\boldsymbol{P}$ & $r^{2}$ & $\boldsymbol{P}$ & $\boldsymbol{r}^{2}$ & $\boldsymbol{P}$ \\
\hline Log(SVL)/log(Clutch size) & 0.005 & 0.2387 & 0.007 & 0.2299 & 0.001 & 0.7185 \\
\hline Log(SVL)/log(Latitude) & 0.041 & $<0.0001 *$ & 0.044 & $0.0020 *$ & 0.101 & $<0.0001 *$ \\
\hline Log(SVL)/log(Elevation) & 0.0001 & 0.8119 & 0.001 & 0.6526 & 0.018 & 0.0967 \\
\hline $\begin{array}{l}\text { Log(SVL)/log(Mean annual } \\
\text { temperature) }\end{array}$ & 0.043 & $<0.0001^{*}$ & 0.033 & $0.0076 *$ & 0.074 & $0.0006 *$ \\
\hline $\begin{array}{l}\log (S V L) / \log (\text { Mean annual } \\
\text { precipitation) }\end{array}$ & 0.007 & 0.0593 & 0.015 & 0.0726 & 0.066 & $0.0013 *$ \\
\hline Log(Clutch size)/log(Latitude) & 0.073 & $<0.0001^{*}$ & 0.065 & $0.0002 *$ & 0.0009 & 0.2268 \\
\hline Log(Clutch size)/log(Elevation) & 0.053 & $<0.0001 *$ & 0.065 & $0.0002 *$ & 0.009 & 0.2328 \\
\hline $\begin{array}{l}\text { Log(Clutch size)/log(Mean annual } \\
\text { temperature) }\end{array}$ & 0.055 & $<0.0001^{*}$ & 0.048 & $<0.0013^{*}$ & 0.007 & 0.3130 \\
\hline $\begin{array}{l}\text { Log(Clutch size)/log(Mean annual } \\
\text { precipitation) }\end{array}$ & 0.016 & $0.0383 *$ & 0.018 & 0.0532 & 0.00006 & 0.9656 \\
\hline
\end{tabular}
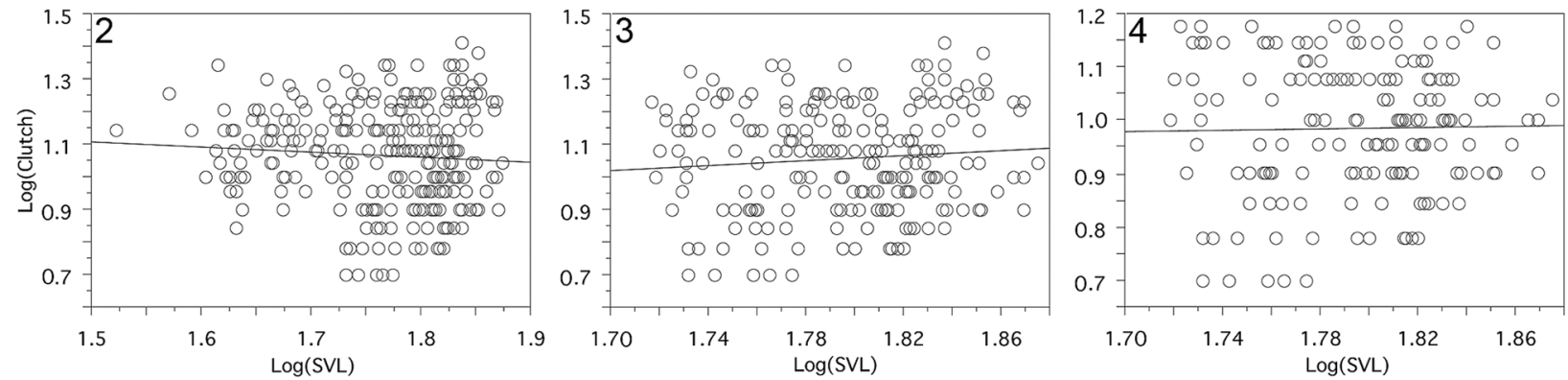

Fig. 2. Simple regression graphs of $\log ($ clutch size) versus $\log (\mathrm{SVL})$ in female Common Five-lined Skinks (Plestiodon fasciatus). Numbers represent categories: Category $2=$ all females with with either yolked ovarian follicles or oviductal eggs; Category $3=$ females with either yolked ovarian follicles or oviductal eggs and SVL > $52 \mathrm{~mm}$; Category 4 = females with SVL > $52 \mathrm{~mm}$ and with clutch sizes determined solely by the presence of oviductal eggs. No relationships were significant (Table 2 ). 

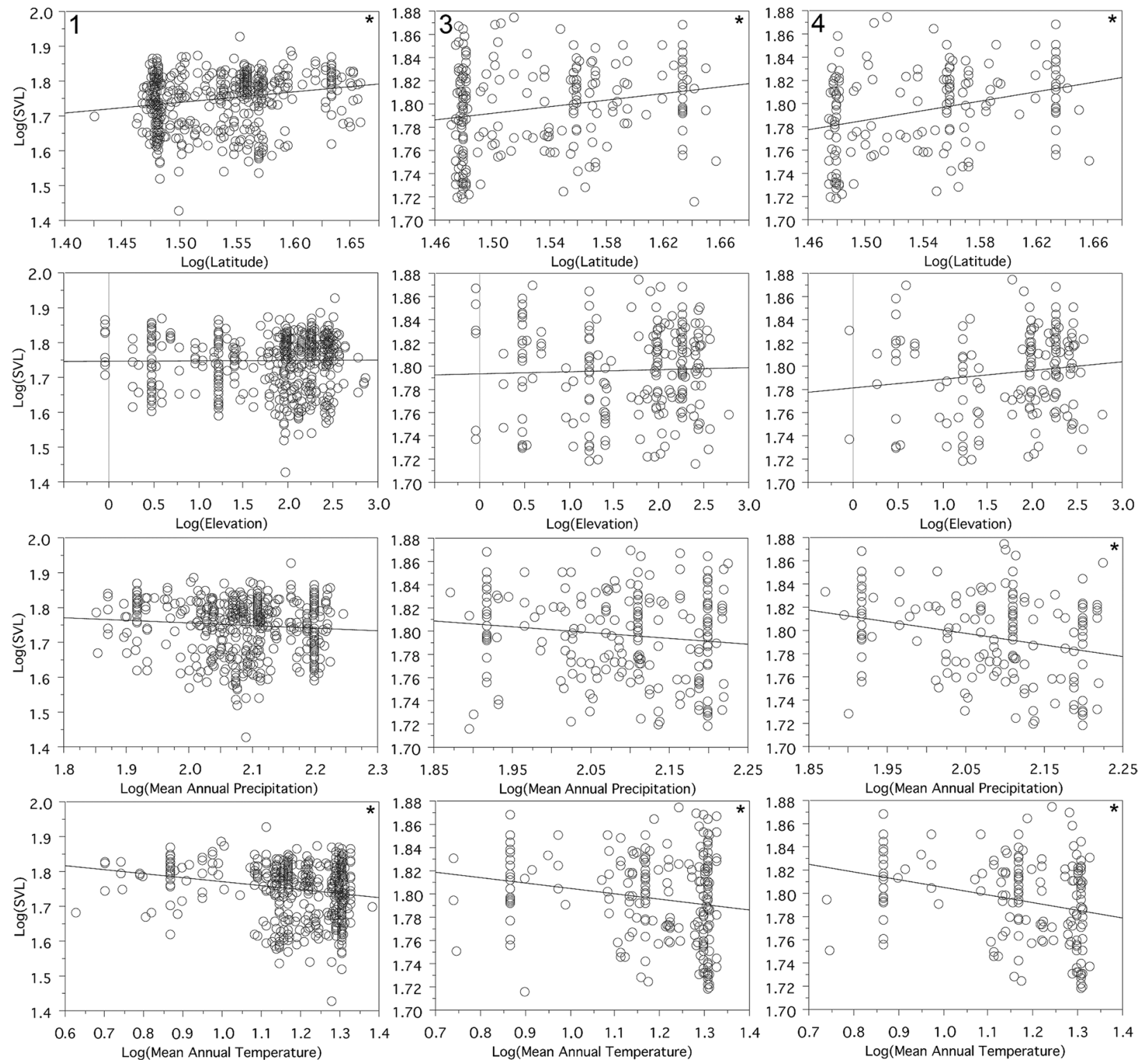

Fig. 3. Simple regression graphs of $\log (\mathrm{SVL})$ versus the $\log _{10}$ of four environmental variables in female Common Five-lined Skinks (Plestiodon fasciatus). Numbers represent categories: Category $1=$ all females; Category $3=$ females with either yolked ovarian follicles or oviductal eggs and SVL > $52 \mathrm{~mm}$; Category 4 = females with SVL > $52 \mathrm{~mm}$ and with clutch sizes determined solely by the presence of oviductal eggs. Significant relationships are marked with an asterisk $\left(^{*}\right)$. See also Table 2.

Trends in body size.-Unlike Lowes and Lougheed (2007), who found that male body size increased with latitude (following Bergmann's rule, but contrary to the conclusions of Ashton and Feldman, 2003) but that female body size was relatively constant throughout the species' range, we found considerable variation in female body size. The negative association between SVL and temperature and the positive association of SVL and latitude lends support for the contention that female skinks either follow Bergmann's rule, contrary to Ashton and Feldman's (2003) analysis and our prediction, or that the temperature-size rule might apply. The equivocal associations between SVL and mean annual precipitation could suggest that the expected effects of precipitation were at least to some degree offset by factors that could include seasonal variation in rainfall (e.g., Aragón and Fitze, 2014) and its relationship to growth or perhaps some level of productivity despite cooler temperatures and less rainfall in northern parts of the species' range. Alternatively, effective microhabitat selection by northern females (e.g., Hecnar, 1994; Hecnar and M'Closkey, 1998; see also below) could compensate for presumably inhospitable climatic conditions. We suggest that the relatively limited elevational range represented in our samples limited our ability to detect any associations with elevation.

Tentative support for the temperature-size rule is evident in minimum body size or age at sexual maturity. The smallest female with yolked ovarian follicles (from Texas) had a SVL of $33.2 \mathrm{~mm}$, which was considerably 

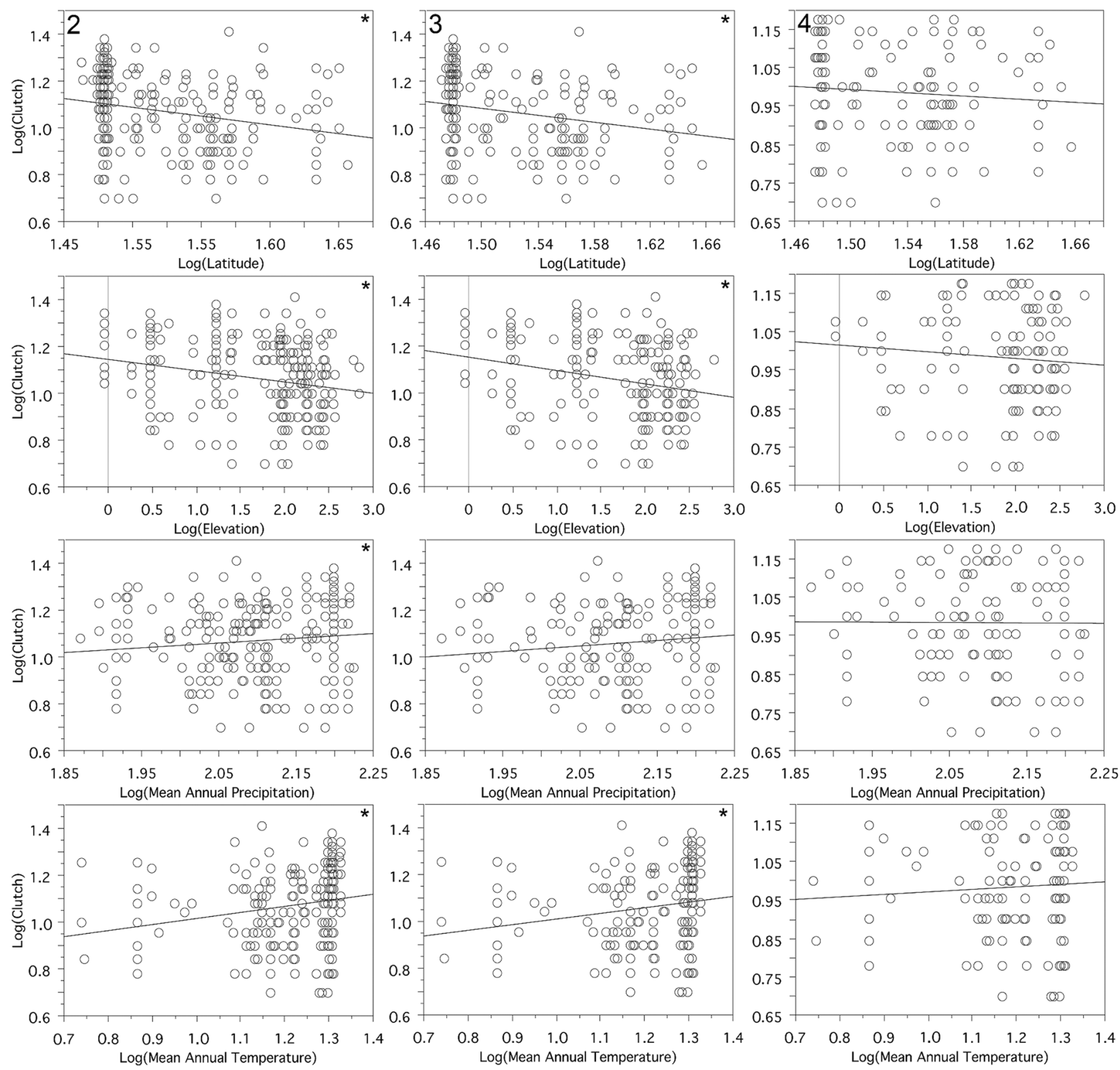

Fig. 4. Simple regression graphs of $\log$ (clutch size) versus the $\log _{10}$ of four environmental variables in female Common Five-lined Skinks (Plestiodon fasciatus). Numbers represent categories: Category $2=$ all females with with either yolked ovarian follicles or oviductal eggs; Category 3 = females with either yolked ovarian follicles or oviductal eggs and SVL > $52 \mathrm{~mm}$; Category $4=$ females with $\mathrm{SVL}>52 \mathrm{~mm}$ and with clutch sizes determined solely by the presence of oviductal eggs. Significant relationships are marked with an asterisk $(*)$. See also Table 2 .

smaller than expected. Although we cannot rule out the possibility that follicles do not fully develop in younger females or that the yellowish coloration of follicles in some females was an artifact of preservation, the color of follicles in the smaller lizards was consistent with that of obvious vitellogenic follicles in larger specimens. Fitch (1954) indicated that females reach maturity in their second spring, and Vitt and Cooper (1986) stated that sexual maturity was achieved at $\mathrm{SVL}=52 \mathrm{~mm}$ in the southeastern United States. However, based on the sizes of the smallest individuals with yolked ovarian follicles and growth data presented by Fitch (1954) and Seburn (1990), our data suggest that at least some females be- gin vitellogenesis during their first full year of life. That said, the smallest female in our sample (from Arkansas) with oviductal eggs had a SVL of $53.1 \mathrm{~mm}$, and all of the smaller females with yolked follicles were from the southern half of the species' range, where maturation apparently is achieved at smaller body sizes.

Our seemingly counterintuitive findings of larger mean adult female body size in northern areas, where productivity appears to be lower than in the south, and smaller minimum body sizes at sexual maturity of females in the south could be explained by the effects of interspecific competition or greater predation pressures. In their study of the southern Florida herpetofauna, Meshaka 
and Layne (2015), contrary to expectations, encountered larger individuals of several species farther north on the Florida Peninsula. The common element in these instances was a reduction in the number of putative interspecific competitors. If such interspecific competition has a negative effect on body size in Common Five-lined Skinks, that effect would be least evident in the most northerly populations, which have no sympatric congeners (e.g., Powell et al., 2016), and most intense in the southern portions of the species' range, where a number of sympatric congeners ( $P$. anthracinus, $P$. inexpectatus, $P$. laticeps) could be competing for many of the same essential resources. That also could explain a rapid attainment of sexual maturity followed by stunted adult body sizes in the south. Conversely, individuals in the north can grow larger than would otherwise be expected because of a release from competition, even if the rate of growth is slower than in southern populations because of colder temperatures and shorter growing seasons. Similarly, northern populations are likely subjected to lower predation pressure from a less diverse suite of predators (e.g., Sidorovich, 2011). Although we cannot rule out differences in genetic factors (Howes et al., 2006), a reduction in competition, predation, or both could result in enhanced survival, longer periods for growth (even at slower rates), and larger average adult body size.

Also, although our data suggest that environmental factors can influence body size, albeit in a direction opposite to our predictions and those of Ashton and Feldman (2003), we suggest that any conclusions could be compromised by the effective exploitation of microhabitats by northern females (e.g., Hecnar, 1994; Hecnar and M'Closkey, 1998), especially since our environmental data did not reflect the exact localities, much less the microhabitats, where specimens had been collected. Common Five-lined Skinks are closely associated with moist wooded areas throughout their range (e.g., Fitch, 1954; Hecnar, 1994; Environment Canada, 2014). By restricting activity to microhabitats (e.g., rotting logs) that provide ample food and minimize the potential negative effects of cooler, drier macroclimatic conditions, skinks might avoid the effects on growth normally associated with such environmental factors.

Finally, hatchling size, which we did not assess, can dramatically affect adult sizes. Vitt and Cooper (1986) found significant differences in hatchling sizes among clutches in the southeastern United States. Such variability within a geographic subset of the species' total distribution suggests that considerable variation in body sizes could exist throughout the entire range of the species. If true, that variability could obscure or confound trends attributable to climatic differences.

Trends in clutch size.-That larger females did not produce larger clutches contradicts our prediction and the fact that most reptiles (e.g., Shine, 1988) follow that pattern. Hecnar and Hecnar (2019) documented a significant increase in clutch size with increasing female body size. Brown (1992) examined $16 P$. fasciatus clutches from North Carolina and determined that the largest females tended to produce the most eggs. Vitt and Cooper (1986) documented a similar trend in the southeastern U.S., although the pattern was less evident than in many other species of lizards (i.e., Fitch, 1970). We initially thought that the most logical explanation for why our data did not follow that trend was that many of our putative clutch sizes were based on yolked ovarian follicles, some in very small females, and that vitellogenic follicles do not necessarily translate into ova (e.g., Ramírez-Pinilla et al., 2014). Fitch (1970) listed a maximum clutch size of 18 and Hecnar and Hecnar (2019) recorded a clutch of 19 , but we found 13 individuals with more than 18 yolked ovarian follicles, although our largest observed clutch size based solely on oviductal eggs was 15 . Nevertheless, the relationship between clutch size and female SVL remained insignificant when we excluded females with SVL $<52 \mathrm{~mm}$ or when based solely on oviductal egg counts (Table 2). Trends observed by Brown (1992) and Vitt and Cooper (1986) in the southeastern U.S. might have been obscured by other climatic or life-history variables in other parts of the species' range (see also the discussion in Mesquita et al., 2016) or unknown genetic variables (e.g., Howes et al., 2006) might apply.

In a review of the literature, Hecnar and Hecnar (2019) found no significant relationship between either latitude or longitude and mean clutch size and they suggested that clutch size appeared to be a "generally stable trait across the species geographic range." In our study, the relationship between clutch size and the abiotic environmental factors generated two strikingly different results. Relationships in line with our predictions were evident for categories 2 and 3, although contrary to findings of Pincheira-Donoso and Meiri (2013), whereas regressions for category 4, derived solely from oviductal egg counts in females with SVLs > $52 \mathrm{~mm}$ and most like those reported in Hecnar and Hecnar (2019), with data derived from actual clutches, were not significant. These data suggest that females with clutches that are not fully developed are strongly affected by the productivity associated with warmer, wetter southern areas (i.e., the resource rule). However, final investment in a clutch, as measured by the number of oviductal eggs, appears to be controlled by some other factor or suite of factors, which could include any number of life-history variables (e.g., Mesquita et al., 2016) or something as mundane as sampling bias (i.e., fewer records from northern and eastern portions of the range where skinks are less abundant). We also cannot rule out egg size (and consequently hatchling size), which could be affected by both female body size and productivity. If true, abiotic factors would affect potential clutch size, whereas actual clutch size could be determined by an interplay of female body size and energy.

$r$ - and $K$-selection.-Body sizes of female Common Five-lined Skinks tend to increase with latitude and, although Hecnar and Hecnar (2019) showed a positive albeit insignificant relationship between latitude and clutch sizes, our data, which included samples from many more southerly locations, showed a trend of decreasing clutch sizes with increasing latitude. This could reflect selection for two different regionally dependent life-history strategies. A continuum in life-history strategies variously embodies $r$ - and $K$-selected strategies (e.g., Pianka, 1970). In $P$. fasciatus, two different suites of traits apparently depend on latitude, the reasons for which may be found in an interaction of regionally specific biotic and abiotic factors. We suggest that a combination of competitive release, reduced predation pressure, and temperature-size associations result in northern populations adhering to a predominantly $K$-selected strategy of delayed sexual maturity and larger adult body size. Smaller clutch sizes and presumably larger egg sizes would be associated with high juvenile survivorship if these large females live longer than their southern counterparts. Conversely, the temperature-size rule would select for early maturity at smaller body sizes in the south. We suspect that, despite 
greater resource abundance, the presence of congeneric competitors and greater predation pressure limits growth and lowers adult survivorship. Such selective pressures would favor $r$-selection in southern populations and would also explain the apparently intense pressure on large clutches.

Although our effect sizes are low, we suggest that this is the result of the "noise" generated by a relatively large dataset with considerable and inevitable variation among individuals and populations. Nevertheless, the evident geographic patterns associated with female body and clutch sizes in Common Five-lined Skinks are consistent with predictions of $r$ - and $K$-selection. The selective pressures behind the geographic trends in body size might tentatively be ascribed to a combination of the presence or absence of competitors, greater or lesser predation pressures, and effects of the temperature-size rule. This tentative explanation does not contradict the resource rule with respect to greater productivity in warmer areas but does address the effects resulting from the variable availability of resources on growth and the concomitant diversion of energy to clutch size in skinks that are syntopic with many competitors and predators versus those that are not.

\section{ACKNOWLEDGEMENTS}

We thank W. E. Meshaka and R. W. Henderson for insights and helpful comments on earlier versions of this manuscript. T. W. Taggart provided the base map for Fig. 1. R. M. Brown, R. E. Glor, L. J. Welton, and K. O. Chan (University of Kansas Biodiversity Institute \& Natural History Museum), K. de Queiroz, J. Jacobs, and R. Wilson (National Museum of Natural History, Smithsonian Institution), J. Colby and R. W. Henderson (Milwaukee Public Museum), A. Lathrop and R. W. Murphy (Royal Ontario Museum), G. J. Watkins-Colwell (Yale Peabody Museum of Natural History), J. L. Watters and C. D. Siler (Sam Noble Museum, University of Oklahoma), G. Schneider (Museum of Zoology, University of Michigan), L. D. McBayer, C. R. Evans, and J. H. Oliver Jr. (Institute for Coastal Plain Science, Georgia Southern University), C. D. Austin and S. E. Parker (Louisiana State University Museum of Natural Science), and T. J. LaDuc and K. Hornung (Biodiversity Center, University of Texas at Austin) facilitated the loans of specimens used in this study; C. Opitz, University of Iowa Museum of Natural History, tried very hard to fill some geographic gaps in our samples.

This project was in partial fulfillment of requirements for the senior colloquium and seminar course at Avila University.

\section{LITERATURE CITED}

Abell, A. J. 1999. Variation in clutch size and offspring size relative to environmental conditions in the lizard Sceloporus virgatus. Journal of Herpetology 33:173180.

Amarello, M., E. M. Nowak, E. N. Taylor, G. W. Schuett, R. A. Repp, P. C. Rosen, and D. L. Hardy. 2010. Potential environmental influences on variation in body size and sexual size dimorphism among Arizona populations of the Western Diamond-backed Rattlesnake (Crotalus atrox). Journal of Arid Environments 74:1443-1449.

Angilletta, M. J., Jr., and A.E. Dunham. 2003. The temperature-size rule in ectotherms: Simple evolutionary explanations may not be general. The American Naturalist 162:332-342.
Angilletta, M. J., Jr., T. D. Steury, and M. W. Sears. 2004. Temperature, growth rate, and body size in ectotherms: Fitting pieces of a life-history puzzle. Integrative and Comparative Biology 44:490-509.

Aragón, P., and P. S. Fitze. 2014. Geographical and temporal body size variation in a reptile: Roles of sex, ecology, phylogeny and ecology structured in phylogeny. PLOS ONE 9(8):e104026.

Ashton, K. G., and C. R. Feldman. 2003. Bergmann's rule in nonavian reptiles: Turtles follow it, lizards and snakes reverse it. Evolution 57:1151-1163.

Bergmann, C. 1847. Ueber die Verhältnisse der Wärmeökonomie der Thiere zu ihrer Grösse. Göttinger Studien 3:595-708.

Birdsall, S. S., J. C. Malinowski, and W. C. Thompson. 2017. Regional Landscapes of the United States and Canada. $8^{\text {th }}$ ed. John Wiley \& Sons, Inc., USA.

Brazeau, D. J., R. Freitag, S. J. Hecnar, and D. R. Hecnar. 2015. Comparing Common Five-lined Skink (Plestiodon fasciatus) diet among locations and time. Herpetological Review 46:331-336.

Brown, E. E. 1992. Notes on amphibians and reptiles of the western Piedmont of North Carolina. Journal of the Elisha Mitchell Scientific Society 108:38-54.

Environment Canada. 2014. Recovery Strategy for the Five-lined Skink (Plestiodon fasciatus) - Carolina Population in Canada [Proposed]. Species at Risk Act Recovery Strategy Series. Environment Canada, Ottawa. http://www.registrelep-sararegistry.gc.ca/virtual_sara/files/plans/rs_five-lined_skink_carolinian_ pop_e_proposed.pdf

Fitch, H. S. 1954. Life history and ecology of the Fivelined Skink, Eumeces fasciatus. University of Kansas Publications, Museum of Natural History 8:1-156.

Fitch, H. S. 1970. Reproductive cycles in lizards and snakes. University of Kansas Museum of Natural History, Miscellaneous Publication 52:1-247.

Harding, J. H. 1997. Amphibians and Reptiles of the Great Lakes Region. University of Michigan Press, USA.

Hecnar, S. J. 1994. Nest distribution, site selection, and brooding in the Five-lined Skink (Eumeces fasciatus). Canadian Journal of Zoology 72:1510-1560.

Hecnar, S. J., and D. R. Hecnar. 2005. Five-lined Skink research at Point Pelee National Park 2005. Unpublished report to Parks Canada, Gatineau, Quebec, Canada.

Hecnar, S. J., and D. R. Hecnar. 2019. Clutch size in Plestiodon fasciatus near its northern range boundary and variation across the species range. Herpetological Review 50:712-717.

Hecnar, S. J., and R. T. M'Closkey. 1998. Effects of human disturbance on Five-lined Skink, Eumeces fasciatus, abundance and distribution. Biological Conservation 85:213-222.

Howes, B. J., and S. C. Lougheed. 2007. Male body size varies with latitude in a temperate lizard. Canadian Journal of Zoology 85:626-633.

Howes, B. J., B. Lindsay, and S. C. Lougheed. 2006. Range-wide phylogeography of a temperate lizard, the Five-lined Skink (Eumeces fasciatus). Molecular Phylogenetics and Evolution 40:183-194.

Linnaeus, C. 1758. Systema naturæ per regna tria naturæ, secundum classes, ordines, genera, species, cum characteribus, differentiis, synonymis, locis. Tomus I. Editio decima, reformata. Laurentii Salvii, Holmiæ. 
McNab, B. 2010. Geographic and temporal correlations of mammalian size reconsidered: A resource rule. Oecologia 164:13-23.

Meshaka, W. E., Jr., and J. N. Layne. 2015. The herpetology of southern Florida. Herpetological Conservation and Biology 10 (Monograph 5):1-353.

Mesquita, D. O., G. C. Costa, G. R. Colli, T. B. Costa, D. B. Shepard, L. J. Vitt, and E. R. Pianka. 2016. Life-history patterns of lizards of the world. The American Naturalist 187:689-705.

Olalla-Tárraga, M. A., M. Á. Rodríguez, and B. A. Hawkins. 2006. Broad-scale patterns of body size in squamate reptiles of Europe and North America. Journal of Biogeography 33:781-793.

Oufiero, C. E., S. C. Adolph, G. E. A. Gartner, and T. Garland. 2011. Latitudinal and climatic variation in body size and dorsal scale counts in Sceloporus lizards: A phylogenetic perspective. Evolution 65:3590-3607.

Noble, G. K., and E. R. Mason. 1933. Experiments on the brooding habits of lizards Eumeces and Ophisaurus. American Museum Novitates 619:1-29.

Palmer, W. M., and A. L. Braswell. 1995. Reptiles of North Carolina. The University of North Carolina Press, Chapel Hill, North Carolina, USA.

Pianka, E. R. 1970. On $r$ - and $K$-selection. The American Naturalist 104:592-597.

Pincheira-Donoso, D., and S. Meiri. 2013. An intercontinental analysis of climate-driven body size clines in reptiles: No support for patterns, no signals of processes. Evolutionary Biology 40:562-578.

Powell, R., R. Conant, and J. T. Collins. 2016. Peterson Field Guide to Reptiles and Amphibians of Eastern and Central North America. $4^{\text {th }}$ ed. Houghton Mifflin Harcourt, USA.

Ramírez-Pinilla, M. P., G. R. de Pérez, and C. Alvarado-Ramírez. 2014. Oogenesis and the ovarian cycle. Pp. 213-252 in J.L. Rheubert, D.S. Siegel, and S.E. Trauth (Eds.), Reproductive Biology and Phylogeny of Lizards and Tuatara. Reproductive Biology and Phylogeny, Volume 10. CRC Press, USA.

Seburn, C. N. L. 1990. Population ecology of the Fivelined Skink, Eumeces fasciatus, at Point Pelee National Park, Canada. Unpublished M.S. Thesis, University of Windsor, Windsor, Ontario, Canada.

Seburn, C. N. L., and D. C. Seburn. 1989. The geographical ecology of the Five-lined Skink in Ontario. Unpublished report to the Royal Canadian Geographical Society, Ottawa, Ontario, Canada.

Seburn, C. N. L., and D. C. Seburn. 1998. COSEWIC status report on the Five-lined Skink Eumeces fasciatus in Canada. Committee on the Status of Endangered Wildlife in Canada, Ottawa, Ontario, Canada.

Shine, R. 1988. Parental care in reptiles. Pp. 275-329 in C. Gans and R. B. Huey (Eds.), Biology of the Reptilia. Volume 16, Ecology B. Defense and Life History. Alan R. Liss, Inc., New York, New York, USA.

Sidorovich, V. E. 2011. Analysis of Vertebrate Predator-Prey Community. Tesey, Belarus.

Smith, H. M. 1946. Handbook of Lizards. Lizards of the United States and of Canada. Comstock Publishing Company, USA.

Stillwell, R. C. 2010. Are latitudinal clines in body size adaptive? Oikos 119:1387-1390.

Tracy, C. R. 1999. Differences in body size among chuckwalla (Sauromalus obesus) populations. Ecology 80:259-271.
Vitt, L. J., and W. E. Cooper, Jr. 1986. Skink reproduction and sexual dimorphism: Eumeces fasciatus in the southeastern United States, with notes on Eumeces inexpectatus. Journal of Herpetology 20:65-76.

Volynchik, S. 2012. Morphological variability in Vipera palaestinae along an environmental gradient. Asian Herpetological Research 3:227-239.

Wick, S. E. 2004. Microsatellite analysis of fine-scale population structure in a northern population of the Five-lined Skink (Eumeces fasciatus). Unpublished M.S. Thesis, University of Guelph, Guelph, Ontario, Canada.

Zhao, W., and M. A. K. Khalil. 1993. The relationship between precipitation and temperature over the contiguous United States. Journal of Climate 6:1232-1236.

\section{APPENDIX 1}

Specimens examined (including males and juveniles excluded from analyses).

Institute for Coastal Plain Science, Georgia Southern University, Statesboro: GSU 283, 285, 287-91, 292, $295,300-1,303,306,310,317-8,321,324-5,327-8$, 330-1, 332, 334, 7877, 11903, 24620, 24623, 24627 $(n=30)$.

Biodiversity Institute, University of Kansas, Lawrence: $8279-355,8864-73,8908-34,22660,23205-$ $10,24410-1,24486-90,28850,28854,28856,28858-$ $60,28862,28866,28868-9,28873-4,28877,28879$, 28884, 28887-9, 28893, 30141, 33462, 33464-5, $50858-60,55462,61807-18,61820-1,69398-407$, 97825, 98404-16, 145808-15, 150921-3, 153685-7, $176550-5,176557,176559-61,176572-95,188508$, 203076, 204327-8, 214689-704, 223486, 288737, $289554,317876,317891-2(n=267)$.

Louisiana State University Museum of Natural Science, Baton Rouge: LSUMZ 10206, 10211-2, 10215, $11677,13741,13744,13750,13753-4,17626,18683$, $28829,29635,42570-3,44139,51370-1,57007$, $58223,58580,59504,71713,71717,71722-4,71726$, 71731-4, 71747, 71749, 71752-4, 71759-63, 71765-7, 71769, 71775-9, 71782, 71785, 71815, 71827, 71844, $71849,71861,71868-70,71875,71877,71882,71884-$ 5, 71907-8, 71915, 71917, 71923, 71931, 71942-3, $71946,71961,71964-7,71970,71985,72002,72022-$ 4, 72026, 72035, 72042, 72050, 72192,72296, 73385, $73405-6,83032,84291,84315,84413,86379,87798$, $88674-5,88751-2,89057(n=109)$.

Museum of Zoology, University of Michigan, Ann Arbor: UMMZ 37748-53, 37755-6, 37758-64, 37766, 37768-79, 37781, 37783, 37787, 54375, 58529, 63467, $74486,75856,82101,89507,96460,110650,116324$, $117093,134000(2), 142616,150062,150780,156070$, $156156-7,159172,218577,244717(n=53)$.

Milwaukee Public Museum, Milwaukee, Wisconsin: MPM-RA 489-91, 493, 498, 2424, 3032, 4959, 5031, 5049, 5059, 5173, 5453, 5463, 6583-4, 8559, 8569, $10217,11324,11544-6,11971-2021,12023-36$, $12279,13164,13232,13253,13258,13344-5,13347$, $14252-3,14259-64,14266,14269,14272,14274-5$, 15077-8, 15529-30, 15534-6, 15540, 15542, 15546-9, 15551-3, 16775-6, 17004, 17565, 17567-9, 18742, 
$18963,19055,19088,19090,19233,19628,19643-4$, 19934, 20795, 20798-9, 20801-3, 20805-6, 20809, 20811，21129-31，21185，21479，21481，22511, 22928-30, 22932-4, 25548-9, 23345-6, 28005, 30298, $30319(n=172)$.

Sam Noble Oklahoma Museum of Natural History, University of Oklahoma, Norman: OMNH 24069-70, 25070, 25408-15, 26622, 26918-21, 27062-3, 27086, 28502, 28540-1, 28732, 29159, 29229, 29865, 34177, $34368-9,34539-41,35166,35394,37764-5,38105-7$, 39159-60, 38175-6, 38242, 39484-9, 40094, 40260, $41918-27,41961,44024-8(n=68)$.

Royal Ontario Museum, Toronto, Canada: ROM 111, 113-4, 117, 2101, 2192, 2231, 2813-4, 3450-1, 3972, 4765, 5275, 5543, 5550, 5975, 6399, 7232, 7686, 7768, 7070, 8030, 9281, 9554, 9601, 12020, 22651, 41870, 53564-9 $(n=35)$.

Texas Natural History Collections, Texas Memorial Museum, University of Texas, Austin: TNHC 015001, 01541, 01954-61, 04371, 04381, 04658, 08463, 08465, 08468, 08470-1, 08473, 08476-7, 08779,
09749, 09769, 11761, 12235, 12267, 13297, 13607-9, $13612-3,13615,14260-2,14320,17604-6,19018$, 19022, 19024-7, 19029-30, 19032-3, 20408, 20859, $21181,21447,21711,21713-4,21999,22005,22301-$ $2,22303,24900,25752,25789,28839-40,28844-5$, $28850,29152,31081,31085,31087,32255,32302-$ 7, 33371-4, 52072, 55973, 55985-6, 55989, 55991, 61060, 61063, 89479-80, 91216, 91218, 91220-1, $91224,91227-8(n=117)$.

Peabody Museum of Natural History, Yale University, New Haven, Connecticut: HERR 000890, 0020936, 002885-8, 002895-6, 007308, 011729, 012529, 012656, 013630-1， 013636， 013946-8， 015895, 016230-1, 1018247, $018576(n=26)$.

National Museum of Natural History, Smithsonian Institution, Washington, DC: USNM 4988, 4998, 8801, $9238,13257,13260,13262,13265,15378,35322$, 52466, 53185, 54111, 73812, 92000, 92028, 92060, 92260, 92436, 99205, 99277, 99290, 100809, 132462, 238598-9, 238601-2, 248018，248878，248881, 248883, 313197, 313203-4, 362037, 363119, 468590, $473269,475892,498460(n=41)$. 